\title{
Plasma matrix metalloproteinase-9 levels, MMP-9 gene haplotypes, and cardiovascular risk in obese subjects
}

\author{
Marcelo R. Luizon ${ }^{1}$ Vanessa A. Belo ${ }^{2} \cdot$ Karla S. Fernandes $^{3}$ - Vanessa L. Andrade ${ }^{3}$. \\ Jose E. Tanus-Santos ${ }^{2} \cdot$ Valeria C. Sandrim ${ }^{1}$
}

Received: 10 September 2015/Accepted: 27 April 2016/Published online: 5 May 2016

(C) Springer Science+Business Media Dordrecht 2016

\begin{abstract}
Plasma matrix metalloproteinase (MMP)-9 is a predictor of cardiovascular mortality, and MMP-9 polymorphisms affect plasma MMP-9 levels. However, no study examined whether $M M P-9$ haplotypes affect MMP-9 levels in obese adults. We examined whether MMP-9 polymorphisms and haplotypes are associated with obesity, and whether they affect MMP-9 levels in obese subjects. We examined the plasma levels of MMP-9 and tissue inhibitor of metalloproteinase (TIMP)-1 in 105 subjects with normal weight (controls), 100 obese subjects, and 156 obese subjects with $\geq 3$ metabolic risk factors (MRFs). We determined genotypes for three polymorphisms: C-1562T (rs3918242), Q279R (A>G, rs 17576), and R668Q (G>A, rs17577). MMP-9 levels and activity (MMP-9/TIMP-1 ratio) were higher in obese subjects than in controls $(P<0.05)$. However, MMP-9 levels were higher in obese subjects with $\geq 3$ MRFs than in obese subjects $(P<0.05)$. Obese subjects with $\geq 3$ MRFs carrying the GA+AA genotypes for R668Q $(\mathrm{G}>\mathrm{A})$ polymorphism had higher MMP-9 levels than subjects carrying the AA genotype
\end{abstract}

Electronic supplementary material The online version of this article (doi:10.1007/s11033-016-3993-z) contains supplementary material, which is available to authorized users.

Valeria C. Sandrim

valsandrim@yahoo.com.br

1 Department of Pharmacology, Institute of Biosciences of Botucatu, Universidade Estadual Paulista (UNESP), Distrito de Rubião Junior S/N, Botucatu, SP 18618-000, Brazil

2 Department of Pharmacology, Ribeirao Preto Medical School, University of São Paulo, Av. Bandeirantes, 3900, Ribeirão Preto, SP 14049-900, Brazil

3 Núcleo de Pós-graduação e Pesquisa, Santa Casa de Belo Horizonte, Rua Domingos Vieira, 590, Belo Horizonte, MG 30150-240, Brazil
$(P<0.05)$. The "T, G, A" haplotype was more common in both groups of obese subjects than in controls (OR 3.95 and 4.39 , respectively; $P<0.01$ ). Notably, obese subjects with $\geq 3$ MRFs carrying the " $\mathrm{T}, \mathrm{G}, \mathrm{A}$ " haplotype had higher MMP-9 levels than subjects carrying the " $\mathrm{C}, \mathrm{A}, \mathrm{G}$ " reference haplotype $(P<0.05)$. The "T, G, A" haplotype was associated with an increased risk of obesity and affected MMP-9 levels in obese subjects with $\geq 3$ MRFs. Our findings suggest that plasma MMP-9 levels and MMP-9 haplotypes may help to discriminate obese subjects at an increased cardiovascular risk.

Keywords Haplotypes · Matrix metalloproteinase (MMP)9 - Metabolic risk factors - Obesity · Polymorphisms · Tissue inhibitor of matrix metalloproteinase (TIMP)-1

\section{Introduction}

Matrix metalloproteinase (MMP)-9 is an endopeptidase capable of degrading components of extracellular matrix, and tissue inhibitor of matrix metalloproteinase (TIMP)-1 is a major MMP-9 inhibitor [1]. Plasma MMP-9 concentration was identified as a predictor of mortality in patients with coronary artery disease [2]. Notably, $M M P-9$ was found to be the highest upregulated gene in metabolically unhealthy compared to metabolically healthy obese subjects [3]. Moreover, MMP-9 expression was significantly higher in obese subjects and in obese patients with type 2 diabetes than in subjects with normal weight [4]. Obesity is a key factor in the development of the metabolic syndrome [5], and obese subjects may have an increased risk of developing cardiovascular diseases [6-8].

MMP-9 gene polymorphisms modify plasma MMP-9 levels and prognosis of patients with cardiovascular 
diseases $[2,9,10]$. We have shown that MMP-9 polymorphisms and haplotypes (combinations of genetic markers) affect plasma MMP-9 levels in obese children and adolescents [11]. However, no study has tested the hypothesis that MMP-9 haplotypes are associated with obesity and affect plasma MMP-9 levels in obese adults. It is possible that obese subjects carrying specific $M M P-9$ genotypes or haplotypes may have different plasma MMP9 levels. We focused here on three functional polymorphisms in the MMP-9 gene: C-1562T (rs3918242), Q279R $(\mathrm{A}>\mathrm{G}$, rs17576) and R668Q (G>A, rs17577), which modify MMP-9 expression or activity [10, 12, 13] and have been associated with cardiovascular diseases [2, 9, 14].

In the present study, we aimed at comparing the plasma levels of MMP-9 and TIMP-1, as well as the MMP-9/ TIMP-1 ratios, in subjects with normal weight with those found in obese subjects and in obese subjects with $\geq 3$ metabolic risk factors (MRFs). We then examined whether the $M M P-9$ polymorphisms and haplotypes are associated with the susceptibility to obesity, and whether they affect plasma MMP-9 levels in obese subjects.

\section{Materials and methods}

\section{Subjects}

This study was approved by the Institutional Review Board at the Santa Casa de Belo Horizonte, Brazil, and subjects gave written informed consent. Subjects with obesity were recruited from the Department of Obesity, Center of Medical Specialties of Minas Gerais, Belo Horizonte, Brazil, and the control group consisted of 105 subjects recruited from the local community. Subjects with body mass index $\geq 18.5-24.9 \mathrm{~kg} / \mathrm{m}^{2}$ were considered as having normal weight, and obese subjects were defined as having body mass index $\geq 30 \mathrm{~kg} / \mathrm{m}^{2}$ [15]. Systolic blood pressure (SBP) and diastolic blood pressure (DBP) were measured at least three times from all subjects with the use of an automatic BP device. The individuals were considered hypertensive if their SBP or DBP was $>140$ or $>90 \mathrm{mmHg}$, respectively, or were on antihypertensive therapy.

To determine metabolic risk factors in obese subjects, we followed the diagnostic criteria for metabolic syndrome defined according to the American Heart Association/National Heart, Lung, and Blood Institute Scientific Statement [16], which included the following factors: (1) elevated waist circumference (WC $\geq 120 \mathrm{~cm}$ in men and $\geq 88 \mathrm{~cm}$ in women); (2) elevated triglycerides ( $\mathrm{TG}, \geq 150 \mathrm{mg} / \mathrm{dL}$ or drug treatment for elevated triglycerides); (3) reduced high-density lipoprotein (HDL) cholesterol (HDL-C, $<40 \mathrm{mg} / \mathrm{dL}$ in men and $<50 \mathrm{mg} / \mathrm{dL}$ in women or drug treatment for reduced HDL-C); (4) elevated blood pressure
( $\geq 130 \mathrm{~mm} \mathrm{Hg}$ for SBP or $\geq 85 \mathrm{~mm} \mathrm{Hg}$ for DBP) or drug treatment for elevated blood pressure; (5) elevated fasting glucose $\geq 100 \mathrm{mg} / \mathrm{dL}$ or drug treatment for elevated glucose [16].

At the time of clinical attendance, venous blood samples were collected after overnight fasting, immediately centrifuged at $3000 \mathrm{~g}$ for $10 \mathrm{~min}$ at room temperature, and plasma samples were stored at $-80{ }^{\circ} \mathrm{C}$ until analyzed. Genomic DNA was extracted from the cellular component of $1 \mathrm{~mL}$ of whole blood by a salting-out method and stored at $-20{ }^{\circ} \mathrm{C}$ until analyzed.

\section{Enzyme immunoassays of MMP-9 and TIMP-1 levels and biochemical analyses}

Plasma levels of MMP-9 and TIMP-1 were measured using commercially available enzyme-linked immunosorbent assay (ELISA) kits (R\&D Systems, Minneapolis, MN, USA) according to the manufacturer's instructions. Glucose concentrations and lipid parameters were determined with routine enzymatic methods using commercial kits (Katal Biotechnology Industry and Trade Ltd., Belo Horizonte, Minas Gerais, Brazil).

\section{Genotype determination}

Genotypes for C-1562T (rs3918242) polymorphism in the promoter region of MMP-9 gene were determined by polymerase chain reaction-restriction fragment length polymorphism (PCR-RFLP), as described in detail elsewhere [17]. Briefly, amplified products obtained from PCR were digested with $S p h$ I restriction enzyme, and fragments were separated by electrophoresis in $12 \%$ polyacrylamide gels and visualized by silver staining [17].

Genotypes for Q279R (rs17576, A $>$ G; Assay ID: C_11655953_10) and R668Q (rs17577, G>A; Assay ID: C_11655948_1_) polymorphisms in the exon 6 and exon 12 of $M M P-9$ gene were determined by the respective Taqman allele discrimination assays (Applied Biosystems, Carlsbad, CA, USA). Fluorescence from PCR amplification was detected using Eco Real-Time PCR System (Illumina, San Diego, CA, USA) and analyzed with the manufacturer's software.

\section{Haplotype analysis}

Haplotype frequencies were estimated using the Haplo.stats package version 1.6.11 (http://cran.r-project.org/web/ packages/haplo.stats/index.html), as described in detail elsewhere $[14,18]$. To further confirm the haplotype frequencies, we used the Bayesian statistical based program Phase version 2.1 (http://www.stat.washington.edu/ste phens/software.html) [19]. Only four haplotypes "C, A, 
G", "C, G, G", "C, G, A" and "T, G, A" had frequencies $>5 \%$ in at least one of the study groups and were considered in the statistical analysis. However, we considered a value of $\mathrm{P}_{\mathrm{c}}<0.00625(0.05 / 8$, the total number of possible haplotypes) for the differences in haplotype frequencies among the groups tested using $\chi^{2}$ tests, to correct for the number of comparisons made (Bonferroni's correction). Linkage disequilibrium (LD) among MMP-9 polymorphisms for the study groups were characterized by calculating $D^{\prime}$ and log of the likelihood odds ratio (LOD, a measure of confidence in the value of $D^{\prime}$ ) using the Haploview software (version 4.2; http://www.broad.mit.edu/ mpg/haploview/).

To further examine the effects of $M M P-9$ haplotypes on plasma MMP-9 levels, we compared the haplotype distributions in two extreme groups of subjects: the lower quartile and the upper quartile groups, which included subjects in the lower and in the upper quartiles of plasma MMP-9 distribution, respectively. We hypothesized that the haplotype associated with the higher MMP-9 levels would be more commonly found in the upper quartile group.

\section{Statistical analysis}

The clinical and biochemical characteristics among groups and the effects of genotypes and haplotypes on MMP-9 levels were compared by ANOVA followed by Tukey test (normally distributed variables) or Kruskall-Wallis test followed by Dunn's multiple comparison test (not normally distributed variables). The categorical variables were compared between groups by $\chi^{2}$ tests. The distribution of genotypes for each polymorphism was assessed for deviation from the Hardy-Weinberg equilibrium, and differences in genotype and allele frequencies between groups were assessed using $\chi^{2}$ tests. A value of $P<0.05$ was considered significant. Multivariate linear regression analysis was performed by using the JMP software 5.0.1a (SAS Institute, Cary, NC, USA). Age, gender, body mass index (BMI), and systolic blood pressure (SBP) were considered as independent variables.

Power calculations were performed using the PGA Matlab software (http://dceg.cancer.gov/tools/analysis/pga) [20]. Given the sample size of this study, we obtained a power of $80 \%$ with an alpha level of 0.05 to detect an odds ratio of 2.0, based on the prevalence of obesity as $30 \%$ [8], the disease allele frequency as $6 \%$ for $\mathrm{C}-1562 \mathrm{~T}$ polymorphism (Supplementary Table S1) and the "T, G, A" haplotype frequency as $8.9 \%$ (Table 2).

\section{Results}

The clinical characteristics, anthropometric parameters and biochemical data of subjects included in this study are shown in Table 1. There were significant differences in all factors studied when both groups of obese subjects were compared with subjects with normal weight $(P<0.05)$, except for SBP and DBP (vs. obese subjects; $P>0.05$ ). Obese subjects had a slightly lower average age.

Table 1 Clinical parameters, biochemical data and metabolic risk factors (MRFs) in the study groups

\begin{tabular}{|c|c|c|c|}
\hline Parameters & $\begin{array}{l}\text { Normal weight } \\
(n=105)\end{array}$ & $\begin{array}{l}\text { Obese subjects } \\
(n=100)\end{array}$ & $\begin{array}{l}\text { Obese subjects with } \geq 3 \\
\text { MRFs }(n=156)\end{array}$ \\
\hline Gender (F/M) & $91 / 14$ & $96 / 4^{\mathrm{a}}$ & $143 / 13$ \\
\hline Age (years) & $44 \pm 17$ & $38 \pm 10^{\mathrm{a}}$ & $45 \pm 10^{\mathrm{b}}$ \\
\hline \multicolumn{4}{|l|}{ Anthropometry } \\
\hline Body mass index $\left(\mathrm{kg} \mathrm{m}^{-2}\right)$ & $22 \pm 2.0$ & $41 \pm 9^{\mathrm{a}}$ & $49 \pm 9^{\mathrm{a}, \mathrm{b}}$ \\
\hline Waist circumference $(\mathrm{cm})$ & $80.7 \pm 11.8$ & $115.3 \pm 24.8^{\mathrm{a}}$ & $130.7 \pm 18^{\mathrm{a}, \mathrm{b}}$ \\
\hline \multicolumn{4}{|l|}{ Traditional MRFs } \\
\hline SBP (mm Hg) & $123.2 \pm 16.5$ & $122.3 \pm 13.7$ & $135.8 \pm 20.9^{\mathrm{a}, \mathrm{b}}$ \\
\hline DBP (mm Hg) & $75.7 \pm 9.8$ & $75.9 \pm 9.9$ & $84.5 \pm 12.1^{\mathrm{a}, \mathrm{b}}$ \\
\hline Total cholesterol $\left(\mathrm{md} \mathrm{dL}^{-1}\right)$ & $134.8 \pm 72.6$ & $178.7 \pm 29.8^{\mathrm{a}}$ & $182.1 \pm 39.2^{\mathrm{a}}$ \\
\hline LDL cholesterol $\left(\mathrm{md} \mathrm{dL}^{-1}\right)$ & $100.9 \pm 28.2$ & $113.8 \pm 28.7^{\mathrm{a}}$ & $114.1 \pm 29.4^{\mathrm{a}}$ \\
\hline HDL cholesterol $\left(\mathrm{md} \mathrm{dL}^{-1}\right)$ & $58.9 \pm 13.1$ & $44.4 \pm 10.4^{\mathrm{a}}$ & $45.5 \pm 11.7^{\mathrm{a}}$ \\
\hline Triglycerides $\left(\mathrm{md} \mathrm{dL}^{-1}\right)$ & $103.1 \pm 46.2$ & $118.6 \pm 38.6^{\mathrm{a}}$ & $140.8 \pm 62^{\mathrm{a}, \mathrm{b}}$ \\
\hline Fasting glucose $\left(\mathrm{mg} \mathrm{dL}^{-1}\right)$ & $82.3 \pm 13.5$ & $86.8 \pm 14.9^{\mathrm{a}}$ & $112.2 \pm 45^{\mathrm{a}, \mathrm{b}}$ \\
\hline
\end{tabular}

Values are the mean \pm SD or number of subjects

$D B P$ diastolic blood pressure; $F$ female; $H D L$ high-density lipoprotein; $L D L$ light-density lipoprotein; $M$ male; $S B P$ systolic blood pressure

${ }^{a} P<0.05$ versus subjects with normal weight

b $P<0.05$ versus obese subjects 
Normal weight

Obese subjects

Obese with $\geq 3$ MRFs

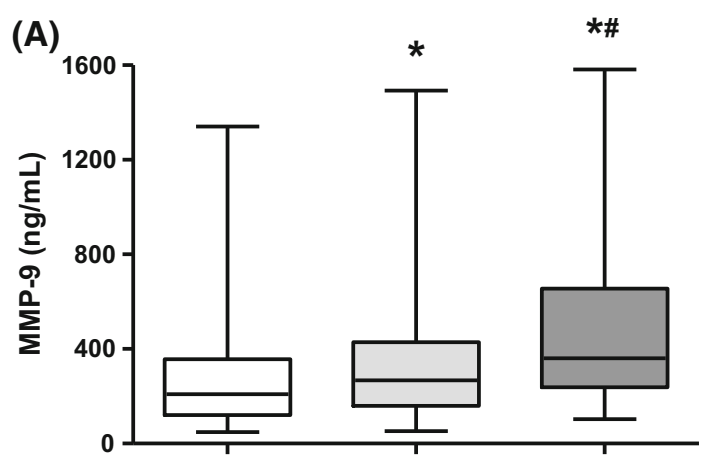

(B)

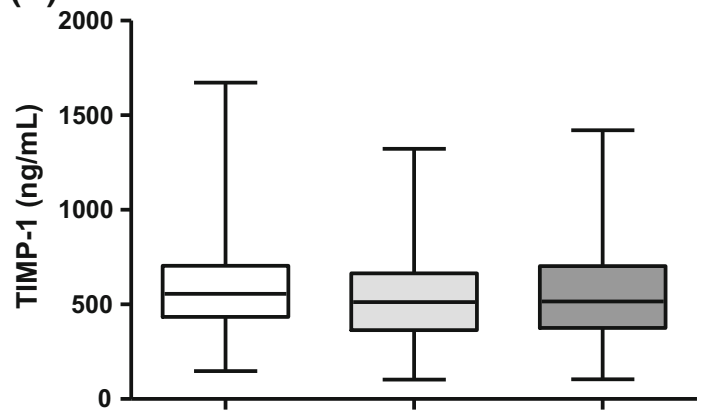

(C)

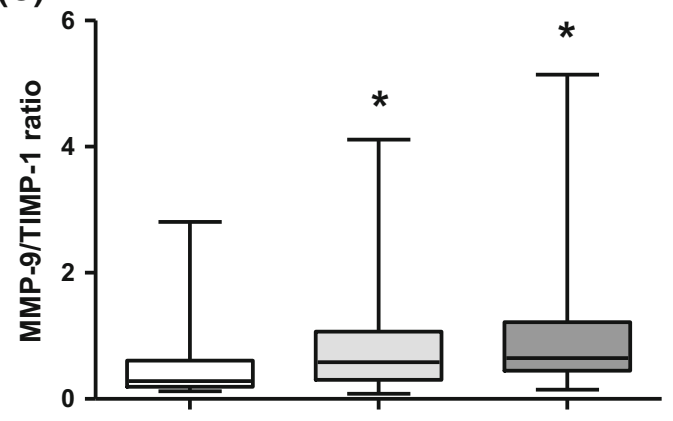

Fig. 1 Plasma MMP-9 levels (a), TIMP-1 levels (b) and MMP-9/ TIMP-1 ratios (c) in subjects with normal weight $(n=105)$, obese subjects $(n=100)$ and obese subjects with $\geq 3$ metabolic risk factors (MRFs) $(n=156)$. The box and whiskers plots show range and quartiles. The boxes extend from the 25 th to the 75 th percentile, with a line at the median. The whiskers show the highest and the lowest values. ${ }^{*} P<0.05$ versus subjects with normal weight. ${ }^{\#} P<0.05$ versus obese subjects

Importantly, the group of obese subjects with $\geq 3$ MRFs had higher body mass index, waist circumference, SBP, DBP, triglycerides and fasting glucose than the group of obese subjects $(P<0.05$; Table 1$)$.

We found higher plasma MMP-9 levels and MMP-9/ TIMP-1 ratios when both groups of obese subjects were compared with subjects with normal weight $(P<0.05$;
Fig. 1a, c, respectively). However, we found no differences in TIMP-1 levels among the groups $(P>0.05$; Fig. 1b). Notably, obese subjects with $\geq 3$ MRFs had higher MMP-9 levels than obese subjects $(P<0.05$; Fig. 1a). We examined the association between plasma MMP-9 levels, BMI and the MRFs in the study groups using linear regression adjusting for age and gender (Table 2). We found that both BMI and SBP were positively correlated with plasma MMP-9 levels in obese subjects with $\geq 3$ MRFs $(P<0.05$; Table 2).

Genotypes and allele frequency distributions for the MMP-9 polymorphisms are shown in Supplementary Table S1. The distributions of genotypes for each polymorphism showed no deviation from Hardy-Weinberg equilibrium. The $\mathrm{CT}+\mathrm{TT}$ genotypes (OR 2.49; $P=0.009$ ) and the $\mathrm{C}$ allele (OR 2.49; $P=0.006$ ) for the $\mathrm{C}-1562 \mathrm{~T}$ polymorphism were found at higher frequency in obese subjects with $\geq 3$ MRFs than in subjects with normal weight (Supplementary Table S1). The CT+TT genotypes were combined for the analysis because there were few subjects with the TT genotype in the study groups. Conversely, we found no differences for the $Q 279 R(A>G)$ and R668Q $(\mathrm{G}>\mathrm{A})$ polymorphisms when the study groups were compared $(P>0.05$; Supplementary Table S1).

We then examined the effects of $M M P-9$ genotypes on plasma MMP-9 levels. We found no effects of the C-1562T and Q279R $(\mathrm{A}>\mathrm{G})$ polymorphisms on MMP-9 levels (Fig. 2a, b, respectively; $P>0.05$ ). However, we found that obese subjects with $\geq 3$ MRFs carrying the GA+AA genotypes had higher MMP-9 levels than subjects carrying the AA genotype for the R668Q $(\mathrm{G}>\mathrm{A})$ polymorphism $(P<0.05$; Fig. $2 \mathrm{c})$. We also examined the effects of $M M P-9$ genotypes on MMP-9 levels using multiple linear regression adjusting for age, gender, BMI and SBP. We found that the GG genotype for the R668Q (G>A) polymorphism was negatively associated with MMP-9 levels in obese subjects with $\geq 3$ MRFs ( $P=0.069$; Supplementary Table S2), which is in agreement with Fig. 2C.

Haplotype frequencies are shown in Table 3. The " $\mathrm{C}, \mathrm{G}$, A" haplotype was found at higher frequency in subjects with normal weight than in both groups of obese subjects (both $P<0.00625$; Table 3). Conversely, the "T, G, A" haplotype was found at higher frequency in both groups of obese subjects than in subjects with normal weight (both $P<0.00625$; Table 3).

Importantly, we examined the effects of different $M M P$ 9 haplotypes on plasma MMP-9 levels. We found no effects on MMP-9 levels when the haplotypes were compared in subjects with normal weight and in obese subjects $(P>0.05$; Fig. 3$)$. The "C, G, A" haplotype was not considered for obese subjects, because there were too few subjects to conduct haplotype analysis in this group. Notably, obese subjects with $\geq 3$ MRFs carrying the " $T$, G, 
Table 2 Effects of BMI and SBP on plasma MMP-9 levels after adjusting for age and gender for the study groups

\begin{tabular}{|c|c|c|c|c|c|c|}
\hline \multirow[t]{3}{*}{ Source } & \multicolumn{6}{|c|}{ MMP-9 (ng/mL) } \\
\hline & \multicolumn{2}{|c|}{ Normal weight } & \multicolumn{2}{|c|}{ Obese subjects } & \multicolumn{2}{|c|}{$\begin{array}{l}\text { Obese subjects with } \\
\geq 3 \mathrm{MRFs}\end{array}$} \\
\hline & $\begin{array}{l}\mathrm{R}^{2} \\
0.686 \\
\mathrm{~B}\end{array}$ & $\begin{array}{l}\text { RMSE } \\
0.172 \\
P\end{array}$ & $\begin{array}{l}\mathrm{R}^{2} \\
0.118 \\
\mathrm{~B}\end{array}$ & $\begin{array}{l}\text { RMSE } \\
0.282 \\
P\end{array}$ & $\begin{array}{l}\mathrm{R}^{2} \\
0.083 \\
\mathrm{~B}\end{array}$ & $\begin{array}{l}\text { RMSE } \\
0.222 \\
P\end{array}$ \\
\hline Female (vs. male) & - & - & -0.114 & 0.279 & 0.028 & 0.435 \\
\hline Age (years) & -0.113 & 0.279 & -0.004 & 0.263 & 0.003 & 0.145 \\
\hline BMI $\left(\mathrm{kg} \mathrm{m}^{-2}\right)$ & -0.052 & 0.202 & 0.008 & $0.012 *$ & 0.004 & $0.045^{*}$ \\
\hline $\mathrm{SBP}(\mathrm{mm} \mathrm{Hg})$ & 0.007 & 0.478 & -0.0002 & 0.939 & 0.002 & $0.042 *$ \\
\hline
\end{tabular}

$B$ parameter estimates for each term; $B M I$ body mass index; MMP-9 Matrix Metalloproteinase 9; MRFs Metabolic Risk Factors; $R^{2}$ proportion of the variation in the response around the mean that can be attributed to terms in the model rather than to random error; RMSE root mean square error; SBP systolic blood pressure

* Statistically significant $(P<0.05)$
A" haplotype had higher MMP-9 levels than subjects carrying the "C, A, G" reference haplotype $(P<0.05$; Fig. 3). We also examined the effects of MMP-9 haplotypes on MMP-9 levels using multiple linear regression adjusting for age, gender, BMI and SBP. We found that the "T, G, A" haplotype was positively associated with MMP9 levels in obese subjects with $\geq 3$ MRFs $(P=0.070$; Supplementary Table S3), which is in agreement with Fig. 3.

We compared the LD among the MMP-9 polymorphisms and we found higher LD values in obese subjects with $\geq 3$ MRFs (Fig. 4). The C-1562T polymorphism (rs3918242) is in high LD with the rs17576 and rs17577 polymorphisms in the exon $6\left(D^{\prime}=0.912, \mathrm{LOD}=11.68\right)$ and exon $12\left(D^{\prime}=0.789\right.$, LOD $\left.=18.11\right)$, respectively, which form a haplotype block in obese subjects with $\geq 3$ MRFs (Fig. 4).

We performed a further analysis and compared the haplotype frequencies for the subjects in the lower and in the upper quartiles of plasma MMP-9 levels distribution within each study group. No significant differences were found in subjects with normal weight and in obese subjects (data not shown). Notably, the "T, G, A" haplotype was more frequent in the upper than in the lower quartile group in obese subjects with $\geq 3$ MRFs (OR 5.09; $P=0.009$; Supplementary Table S4).

\section{Discussion}

The main novel findings of this study are that plasma MMP-9 levels were significantly higher in obese subjects with $\geq 3$ MRFs compared to obese subjects. In addition, obese subjects with $\geq 3$ MRFs carrying the GA+AA genotypes for R668Q (G>A) polymorphism or the "T, $\mathrm{G}, \mathrm{A}$ " haplotype of the MMP-9 gene had higher plasma MMP-9 levels. Furthermore, we found that the "T, G, A" haplotype was associated with an increased risk of obesity.

Both groups of obese subjects had higher plasma MMP9 levels than subjects with normal weight. Consistently, higher MMP-9 levels were found in obese women than lean women [21, 22], and in obese patients than controls [23]. Notably, the MMP-9/TIMP-1 ratios were significantly higher in both groups of obese subjects than subjects with normal weight. The ratio was used to assess net MMP-9 activity because TIMP-1 is a major MMP-9 inhibitor [1]. Therefore, the MMP-9/TIMP-1 ratio might provide a better index of net MMP-9 activity as compared with the simple assessment of MMP-9 levels [11].

Notably, plasma MMP-9 levels were significantly higher in obese subjects with $\geq 3$ MRFs. Indeed, MMP-9 is one of the matrix metalloproteinases most associated with metabolic syndrome $[24,25]$. Increased concentrations of proMMP-9 were associated with increased concentrations of pro-inflammatory mediators in patients with metabolic syndrome [26]. Moreover, elevated expression of pro-inflammatory genes, including $M M P-9$, decreased significantly after weight loss in obese women [27]. In addition, dysregulated production or secretion of adipokines owing to adipose tissue dysfunction can contribute to the development of cardiovascular diseases related to obesity [2830]. Therefore, an increased pro-inflammatory state could explain the highest MMP-9 levels in obese subjects with $\geq 3$ MRFs. However, further studies are needed to prove this hypothesis.

Interestingly, the higher plasma MMP-9 levels in obese subjects with $\geq 3$ MRFs carrying the GA+AA 


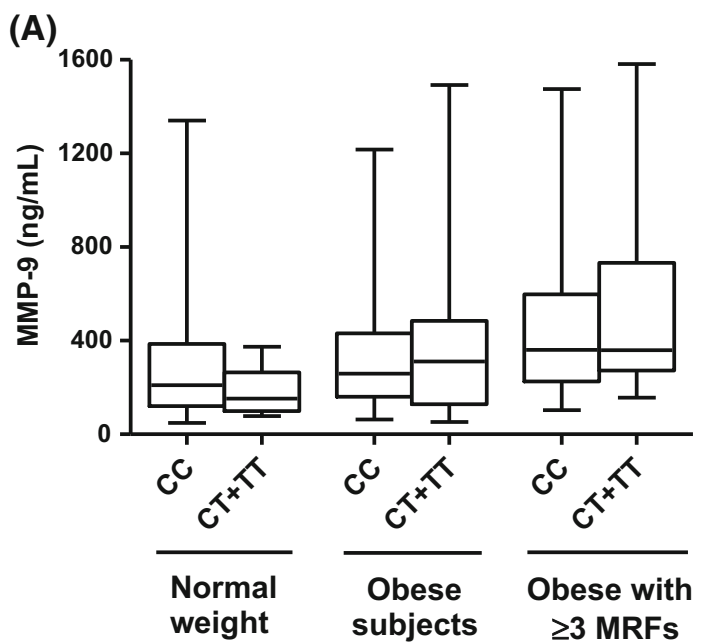

(B)
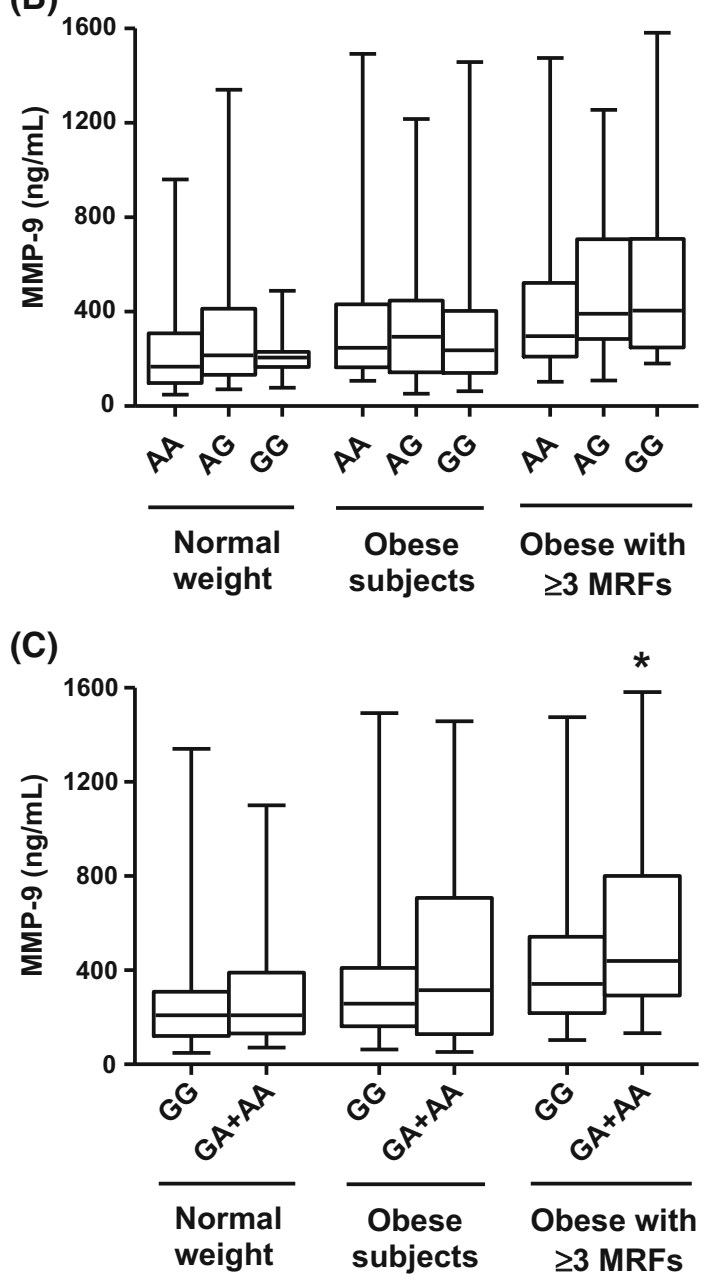

Fig. 2 Plasma MMP-9 levels in subjects with normal weight $(n=105)$, obese subjects $(n=100)$ and obese subjects with $\geq 3$ metabolic risk factors (MRFs) $(n=156)$, grouped according to different genotypes for the $M M P-9$ polymorphisms $(\mathbf{a}-\mathbf{c})$. The box and whiskers plots show range and quartiles. The boxes extend from the 25 th to the 75 th percentile, with a line at the median. The whiskers show the highest and the lowest values. $* P<0.05$ versus the GG genotype in obese subjects with $\geq 3$ MRFs genotypes of R668Q (G>A) polymorphism can be explained by its functional role on $M M P-9$ expression. The microRNA miR-4783-3p preferentially inhibits the $\mathrm{G}$ allele and reduce the MMP-9 protein, but have little effect on the A allele [13], which is in line with the higher MMP-9 levels in subjects carrying the genotypes containing the A allele of this polymorphism. Conversely, the C-1562T polymorphism had no effects on MMP-9 levels, which is in agreement with a previous finding [31]. However, the $\mathrm{T}$ allele of this polymorphism is associated with increased $M M P-9$ expression as a result of the loss of a nuclear repressor protein binding site when the $\mathrm{T}$ allele is present in the promoter region of the MMP-9 gene [10].

We provide the first evidence that $M M P-9$ haplotypes may be associated with the susceptibility to obesity in adults. Particularly, the "T, G, A" haplotype may be associated with an increased risk of obesity. Importantly, while we have shown that MMP-9 haplotypes affect plasma MMP-9 levels in obese children and adolescents [11], this is the first study to examine the effects of MMP-9 haplotypes on plasma MMP-9 levels in obese adults. Higher plasma MMP-9 levels were found in obese subjects with $\geq 3$ MRFs carrying the " $T, G, A$ " haplotype, which was confirmed to be associated with the group of subjects in the upper quartile of MMP-9 levels distribution in this group. Our findings suggest that the "T, G, A" haplotype not only is associated with an increased risk of obesity, but also to higher plasma MMP-9 levels in obese subjects with $\geq 3$ MRFs.

The $\mathrm{C}-1562 \mathrm{~T}$ polymorphism in the promoter region had no effect in the present study, but it could be in LD with another functional polymorphism of $M M P-9$ gene. Although there are differences in LD structure between different populations, $M M P-9$ polymorphisms were also found to be in strong LD in patients with coronary artery disease [9], including the C-1562T (rs3918242) and Q279R (rs17576) polymorphisms studied here. Indeed, we found high LD between rs3918242 and R668Q (rs17577) polymorphisms, which were found to be associated with the obese subjects with $\geq 3$ MRFs and to affect plasma MMP-9 levels in this group, respectively.

This study has some limitations. Despite the relatively small number of subjects, we found associations of MMP-9 gene polymorphisms and haplotypes that remained significant after Bonferroni's correction. Moreover, we have not studied the polymorphism $-90(\mathrm{CA})_{14-24}$ in the promoter of the $M M P-9$ gene, which is known to modify $M M P-9$ expression [32], and to affect plasma MMP-9 levels in healthy subjects [17] and in obese children and adolescents [11]. 
Table 3 MMP-9 haplotype frequencies in subjects with normal weight, obese subjects and obese with $\geq 3$ metabolic risk factors (MRFs)

\begin{tabular}{llllllll}
\hline Haplotype & $\begin{array}{l}\text { Normal weight } \\
(n=210)\end{array}$ & $\begin{array}{l}\text { Obese subjects } \\
(n=200)\end{array}$ & $P$ & $\begin{array}{l}\text { Odds ratio }(95 \% \\
\text { confidence interval })\end{array}$ & $\begin{array}{l}\text { Obese subjects with } \geq 3 \\
\text { MRFs }(n=312)\end{array}$ & $\begin{array}{l}P \\
\text { Odds Ratio (95\% } \\
\text { confidence interval) }\end{array}$ \\
\hline C, A, G & 0.628 & 0.665 & 0.5421 & 1.0000 (Reference) & 0.658 & 0.6415 & $1.000($ Reference) \\
C, G, G & 0.197 & 0.189 & 0.9332 & $0.926(0.554-1.549)$ & 0.164 & 0.4164 & $0.769(0.461-1.283)$ \\
C, G, A & 0.111 & 0.028 & $\mathbf{0 . 0 0 2 1} *$ & $0.226(0.082-0.623)$ & 0.042 & $\mathbf{0 . 0 0 3 2 *} 0.346(0.163-0.737)$ \\
T, G, A & 0.024 & 0.089 & $\mathbf{0 . 0 0 6 2} *$ & $3.953(1.267-12.33)$ & 0.108 & $\mathbf{0 . 0 0 0 8 *} 4.396(1.522-12.69)$ \\
& & ${ }^{\mathrm{a}}$ Global-stat $=16.957, d f=4, P$ val $=0.0019 *$ & ${ }^{\mathrm{b}}$ Global-stat $=22.20392, d f=6, P$ val $=0.0011^{*}$ \\
\hline
\end{tabular}

$* \mathrm{P}_{\mathrm{c}}<0.00625(0.05 /$ total number of possible haplotypes) was considered significant versus subjects with normal weight, to correct for the number of comparisons made (Bonferroni's correction). Global-statistics: ${ }^{\text {a }}$ Obese subjects, and ${ }^{\mathrm{b}}$ Obese subjects with $\geq 3$ MRFs versus subjects with normal weight

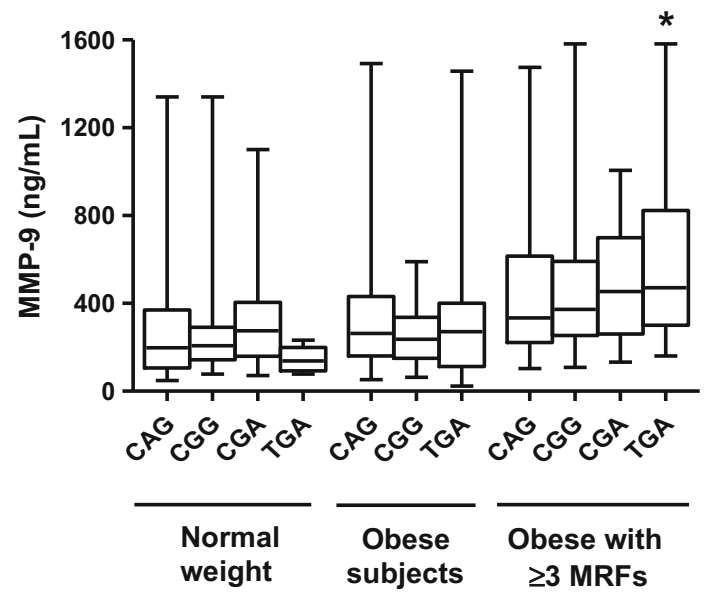

Fig. 3 Plasma MMP-9 levels in the study subjects, grouped according to the different MMP-9 haplotypes. The box and whiskers plots show range and quartiles. The boxes extend from the 25 th to the 75 th percentile, with a line at the median. The whiskers show the highest and the lowest values. $* P<0.05$ versus the " $\mathrm{C}, \mathrm{A}, \mathrm{G}$ " reference haplotype
In conclusion, we found evidence indicating that obese subjects with $\geq 3$ MRFs carrying the GA+AA genotypes for R668Q ( $\mathrm{G}>\mathrm{A})$ polymorphism or the "T, G, A" haplotype of the MMP-9 gene had higher plasma MMP-9 levels. Moreover, we found that the "T, G, A" haplotype is associated with an increased risk of obesity. Our findings suggest that plasma MMP-9 levels and MMP-9 gene haplotypes may help to discriminate obese subjects at an increased cardiovascular risk.

Acknowledgments This study was supported by the Conselho Nacional de Desenvolvimento Científico e Tecnologico (CNPq-Brazil), and by Fundacao de Amparo a Pesquisa do Estado de Minas Gerais (FAPEMIG-Brazil). MRL is a Young Talent Attraction fellow from CNPq-Brazil.

\section{Compliance with ethical standards}

Conflict of interest The authors declare no conflict of interest.
Fig. 4 Linkage disequilibrium (LD) among the $M M P-9$ polymorphisms for the study groups. The polymorphisms are identified by their reference SNP ID number ("rs\#"). Numbers within squares indicate the $D^{\prime}$ value expressed as a percentile. Black squares indicate pairs in strong LD with LOD scores for $\mathrm{LD} \geq 2$, gray squares $D^{\prime}<1$ with $\mathrm{LOD} \geq 2$, and white squares $D^{\prime}<1.0$ and LOD $<2$

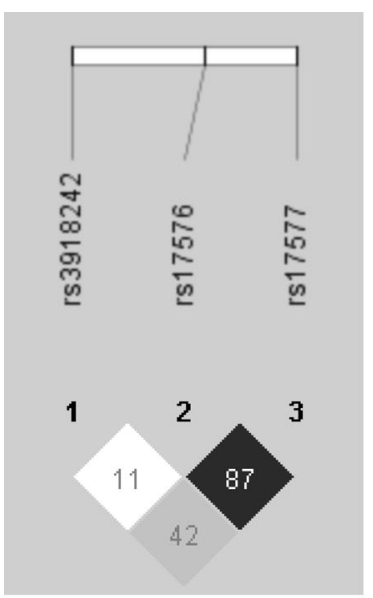

Normal weight

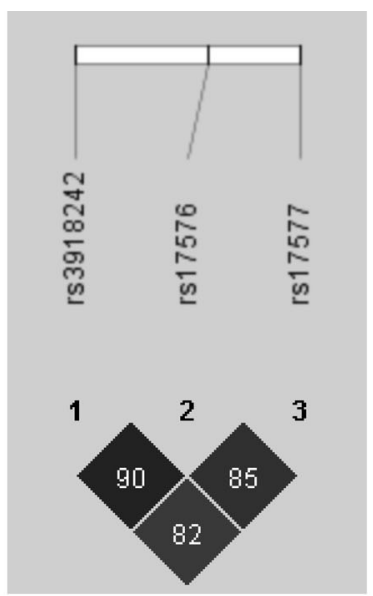

Obese subjects

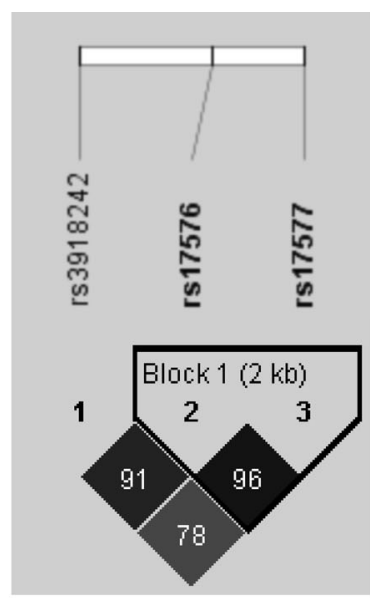

Obese subjects with $\geq 3$ MRFs 


\section{References}

1. Van den Steen PE, Dubois B, Nelissen I, Rudd PM, Dwek RA, Opdenakker G (2002) Biochemistry and molecular biology of gelatinase B or matrix metalloproteinase-9 (MMP-9). Crit Rev Biochem Mol Biol 37(6):375-536. doi:10.1080/104092302907 71546

2. Blankenberg S, Rupprecht HJ, Poirier O, Bickel C, Smieja M, Hafner G, Meyer J, Cambien F, Tiret L, AtheroGene I (2003) Plasma concentrations and genetic variation of matrix metalloproteinase 9 and prognosis of patients with cardiovascular disease. Circulation 107(12):1579-1585. doi:10.1161/01.CIR. 0000058700.41738 .12

3. Das SK, Ma L, Sharma NK (2015) Adipose tissue gene expression and metabolic health of obese adults. Int $\mathrm{J}$ Obes (Lond) 39(5):869-873. doi:10.1038/ijo.2014.210

4. Dandona P, Ghanim H, Monte SV, Caruana JA, Green K, Abuaysheh S, Lohano T, Schentag J, Dhindsa S, Chaudhuri A (2014) Increase in the mediators of asthma in obesity and obesity with type 2 diabetes: reduction with weight loss. Obesity (Silver Spring) 22(2):356-362. doi:10.1002/oby.20524

5. Phillips CM, Tierney AC, Perez-Martinez P, Defoort C, Blaak EE, Gjelstad IM, Lopez-Miranda J, Kiec-Klimczak M, Malczewska-Malec M, Drevon CA, Hall W, Lovegrove JA, Karlstrom B, Riserus U, Roche HM (2013) Obesity and body fat classification in the metabolic syndrome: impact on cardiometabolic risk metabotype. Obesity (Silver Spring) 21(1):E154-E161. doi:10.1002/oby.20263

6. Ahima RS, Lazar MA (2013) Physiology. The health risk of obesity-better metrics imperative. Science. doi:10.1126/science. 1241244

7. Despres JP (2012) Body fat distribution and risk of cardiovascular disease: an update. Circulation 126(10):1301-1313. doi:10. 1161/CIRCULATIONAHA.111.067264

8. Yang W, Kelly T, He J (2007) Genetic epidemiology of obesity. Epidemiol Rev 29:49-61. doi:10.1093/epirev/mxm004

9. Morgan AR, Zhang B, Tapper W, Collins A, Ye S (2003) Haplotypic analysis of the MMP-9 gene in relation to coronary artery disease. J Mol Med (Berl) 81(5):321-326. doi:10.1007/ s00109-003-0441-z

10. Zhang B, Ye S, Herrmann SM, Eriksson P, de Maat M, Evans A, Arveiler D, Luc G, Cambien F, Hamsten A, Watkins H, Henney AM (1999) Functional polymorphism in the regulatory region of gelatinase B gene in relation to severity of coronary atherosclerosis. Circulation 99(14):1788-1794

11. Belo VA, Souza-Costa DC, Luizon MR, Lanna CM, Carneiro PC, Izidoro-Toledo TC, Ferraz KC, Tanus-Santos JE (2012) Matrix metalloproteinase-9 genetic variations affect MMP-9 levels in obese children. Int J Obes (Lond) 36(1):69-75. doi:10.1038/ijo.2011.169

12. Allan JA, Docherty AJ, Barker PJ, Huskisson NS, Reynolds JJ, Murphy G (1995) Binding of gelatinases A and B to type-I collagen and other matrix components. Biochem J 309(Pt 1): 299-306

13. Duellman T, Warren C, Yang J (2014) Single nucleotide polymorphism-specific regulation of matrix metalloproteinase- 9 by multiple miRNAs targeting the coding exon. Nucleic Acids Res 42(9):5518-5531. doi:10.1093/nar/gku197

14. Lacchini R, Jacob-Ferreira AL, Luizon MR, Coeli FB, IzidoroToledo TC, Gasparini S, Ferreira-Sae MC, Schreiber R, Nadruz W Jr, Tanus-Santos JE (2010) Matrix metalloproteinase 9 gene haplotypes affect left ventricular hypertrophy in hypertensive patients. Clin Chim Acta 411(23-24):1940-1944. doi:10.1016/j. cca.2010.08.008

15. Flegal KM, Kit BK, Orpana H, Graubard BI (2013) Association of all-cause mortality with overweight and obesity using standard body mass index categories: a systematic review and metaanalysis. JAMA 309(1):71-82. doi:10.1001/jama.2012.113905

16. Grundy SM, Cleeman JI, Daniels SR, Donato KA, Eckel RH, Franklin BA, Gordon DJ, Krauss RM, Savage PJ, Smith SC Jr, Spertus JA, Costa F, American Heart A, National Heart L, Blood I (2005) Diagnosis and management of the metabolic syndrome: an American Heart Association/National Heart, Lung, and Blood Institute Scientific Statement. Circulation 112(17):2735-2752. doi:10.1161/CIRCULATIONAHA.105.169404

17. Metzger IF, Luizon MR, Lacchini R, Tanus-Santos JE (2012) Genetic variants in matrix metalloproteinase-9 gene modify metalloproteinase-9 levels in black subjects. DNA Cell Biol 31(4):504-510. doi:10.1089/dna.2011.1388

18. Schaid DJ, Rowland CM, Tines DE, Jacobson RM, Poland GA (2002) Score tests for association between traits and haplotypes when linkage phase is ambiguous. Am $J$ Hum Genet 70(2):425-434. doi:10.1086/338688

19. Stephens M, Smith NJ, Donnelly P (2001) A new statistical method for haplotype reconstruction from population data. Am J Hum Genet 68(4):978-989. doi:10.1086/319501

20. Menashe I, Rosenberg PS, Chen BE (2008) PGA: power calculator for case-control genetic association analyses. BMC Genet 9:36. doi:10.1186/1471-2156-9-36

21. Andrade VL, Petruceli E, Belo VA, Andrade-Fernandes CM, Caetano Russi CV, Bosco AA, Tanus-Santos JE, Sandrim VC (2012) Evaluation of plasmatic MMP-8, MMP-9, TIMP-1 and MPO levels in obese and lean women. Clin Biochem 45(6):412-415. doi:10.1016/j.clinbiochem.2012.01.008

22. Kosmala W, Plaksej R, Przewlocka-Kosmala M, KuliczkowskaPlaksej J, Bednarek-Tupikowska G, Mazurek W (2008) Matrix metalloproteinases 2 and 9 and their tissue inhibitors 1 and 2 in premenopausal obese women: relationship to cardiac function. Int J Obes (Lond) 32(5):763-771. doi:10.1038/sj.ijo.0803794

23. Derosa G, Ferrari I, D'Angelo A, Tinelli C, Salvadeo SA, Ciccarelli L, Piccinni MN, Gravina A, Ramondetti F, Maffioli P, Cicero AF (2008) Matrix metalloproteinase-2 and -9 levels in obese patients. Endothelium 15(4):219-224. doi:10.1080/ 10623320802228815

24. Berg G, Miksztowicz V, Schreier L (2011) Metalloproteinases in metabolic syndrome. Clin Chim Acta 412(19-20):1731-1739. doi:10.1016/j.cca.2011.06.013

25. Berg G, Schreier L, Miksztowicz V (2014) Circulating and adipose tissue matrix metalloproteinases in cardiometabolic risk environments: pathophysiological aspects. Horm Mol Biol Clin Investig 17(2):79-87. doi:10.1515/hmbci-2013-0069

26. Goncalves FM, Jacob-Ferreira AL, Gomes VA, Casella-Filho A, Chagas AC, Marcaccini AM, Gerlach RF, Tanus-Santos JE (2009) Increased circulating levels of matrix metalloproteinase (MMP)-8, MMP-9, and pro-inflammatory markers in patients with metabolic syndrome. Clin Chim Acta 403(1-2):173-177. doi:10.1016/j.cca.2009.02.013

27. Sheu WH, Chang TM, Lee WJ, Ou HC, Wu CM, Tseng LN, Lang HF, Wu CS, Wan CJ, Lee IT (2008) Effect of weight loss on proinflammatory state of mononuclear cells in obese women. Obesity (Silver Spring) 16(5):1033-1038. doi:10.1038/oby.2008.37

28. Jung UJ, Choi MS (2014) Obesity and its metabolic complications: the role of adipokines and the relationship between obesity, inflammation, insulin resistance, dyslipidemia and nonalcoholic fatty liver disease. Int J Mol Sci 15(4):6184-6223. doi:10.3390/ijms15046184

29. Ouchi N, Parker JL, Lugus JJ, Walsh K (2011) Adipokines in inflammation and metabolic disease. Nat Rev Immunol 11(2):85-97. doi:10.1038/nri2921

30. Van Gaal LF, Mertens IL, De Block CE (2006) Mechanisms linking obesity with cardiovascular disease. Nature 444(7121):875-880. doi:10.1038/nature05487 
31. Andrade VL, Fernandes KS, Bosco AA, Tanus-Santos JE, Sandrim VC (2012) Functional polymorphism located in MMP-9 gene promoter is strongly associated with obesity. DNA Cell Biol 31(6):1054-1057. doi:10.1089/dna.2011.1526
32. Peters DG, Kassam A, St Jean PL, Yonas H, Ferrell RE (1999) Functional polymorphism in the matrix metalloproteinase-9 promoter as a potential risk factor for intracranial aneurysm. Stroke 30(12):2612-2616 